\title{
Laboreal
}

Volume $4 \mathrm{~N}^{\circ} 1$ | 2008

Ergologia, trabalho, desenvolvimentos

\section{A dimensão relacional do trabalho de auxiliares de enfermagem em Unidade Neonatal : uma análise do ponto de vista da atividade}

La dimensión emparentada del trabajo de auxiliares de enfermería a Unidad

Neonatal : un análisis desde el punto de vista de l' actividad

La dimension relationnelle du travail des aides-soignantes à Unité Neonatal :

une analyse du point de vue de l'activité

The work relational dimension of technician nursemaids within a Neonatal Care

Unit : analysis under the activity point of view

Letícia Pessoa Masson

\section{OpenEdition}

Journals

Edição electrónica

URL: http://journals.openedition.org/laboreal/11988

DOI: $10.4000 /$ laboreal. 11988

ISSN: 1646-5237

Editora

Universidade do Porto

Refêrencia eletrónica

Letícia Pessoa Masson, « A dimensão relacional do trabalho de auxiliares de enfermagem em Unidade Neonatal : uma análise do ponto de vista da atividade », Laboreal [Online], Volume $4 \mathrm{~N}^{0} 1 \mid 2008$, posto online no dia 01 julho 2008, consultado o 24 setembro 2020. URL : http://journals.openedition.org/ laboreal/11988; DOI : https://doi.org/10.4000/laboreal.11988

Este documento foi criado de forma automática no dia 24 setembro 2020.

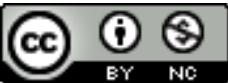

Laboreal está licenciado com uma Licença Creative Commons - Atribuição-NãoComercial 4.0 Internacional. 


\section{A dimensão relacional do trabalho de auxiliares de enfermagem em Unidade Neonatal : uma análise do ponto de vista da atividade}

La dimensión emparentada del trabajo de auxiliares de enfermería a Unidad Neonatal : un análisis desde el punto de vista de l' actividad La dimension relationnelle du travail des aides-soignantes à Unité Neonatal : une analyse du point de vue de l'activité

The work relational dimension of technician nursemaids within a Neonatal Care Unit : analysis under the activity point of view

Letícia Pessoa Masson

\section{REFERÊNCIA}

Masson, L. (2007) A dimensão relacional do trabalho de auxiliares de enfermagem em Unidade Neonatal : uma análise do ponto de vista da atividade. Dissertação de Mestrado em Saúde Pública. Escola Nacional de Saúde Pública/ Fundação Oswaldo Cruz, Rio de Janeiro.

\section{NOTA DO EDITOR}

Manuscrito recebido em : Abril/2008

Aceite após peritagem em : Junho/2008. 


\section{Introdução}

1 Apresentamos uma pesquisa de tese realizada com auxiliares de enfermagem de uma Unidade Neonatal (UN) em uma maternidade pública do Rio de Janeiro, Brasil. 0 estudo buscou compreender-transformar a relação entre a (invisibilidade da) atividade relacional destas trabalhadoras e sua saúde.

2 Entendemos que a produção da invisibilidade da atividade das profissionais denominadas "auxiliares de enfermagem" está vinculada especialmente à histórica divisão sexual e social do trabalho em nossa sociedade, que se constitui em uma norma antecedente (Schwartz, 2000) forte, pois associada à sub-valorização e mesmo à valoração negativa deste coletivo profissional quase inteiramente feminino, considerado pouco escolarizado e qualificado (Scavone, 2005 ; Daune-Richard, 2003; Kergoat, 1996).

3 A saúde é aqui considerada como capacidade normativa, concretizada na recriação permanente do meio, em direção a valores próprios (Canguilhem, 2002). Neste sentido, saúde representa a possibilidade de gerir os riscos, ou seja, de conquistar condições favoráveis para lidar com o sofrimento, dando a ele um rumo criativo, não patogênico. Caminhamos, portanto, ao largo de uma perspectiva exclusivamente baseada em quadros (psico)patológicos eventualmente encontrados.

4 Por atividade relacional entende-se a preponderância do "relacionar-se" próprio dos humanos, o que encontramos no tipo de trabalho realizado por estas profissionais, envolvendo diversos aspectos imbricados e dificilmente isoláveis, tais como a produção linguageira, a dimensão cognitiva e afetivo-emocional, enfim, o envolvimento de todo o corpo na atividade (o corpo-si) (Schwartz \& Durrive, 2007 ; Schwartz, 2000).

\section{Objectivos}

5 A pesquisa teve como objetivos: i) conhecer o enquadre formal do trabalho das auxiliares de enfermagem da UN estudada (normas antecedentes e prescrições) ; ii) aproximar-se da atividade de trabalho e constituir uma Comunidade Ampliada de Pesquisa; iii) contribuir para dar visibilidade aos aspectos ocult(ad)os da atividade destas trabalhadoras como meio de trazer benefícios à relação saúde-trabalho, aliada à qualidade e produtividade.

\section{Referências Teórico-Metodológicas}

6 Tendo como principais referências epistemológicas a concepção canguilheniana de saúde (Canguilhem, 2002) e a perspectiva ergológica (Schwartz \& Durrive, 2007), a pesquisa se pautou teórico-metodologicamente em abordagens clínicas do trabalhar, como a Ergonomia da Atividade (Guérin et al., 2001), o Modelo Operário Italiano de luta pela saúde (Oddone et al., 1986), a Psicodinâmica do Trabalho (Dejours, 2004) e a Clínica da Atividade (Clot, 2006). Utilizamos também as proposições e os estudos sobre a Lógica Competência e a Relação de Serviço (Zarifian, 2001) e a literatura relativa às Relações Sociais de Sexo (Kergoat, 1996).

7 Visou-se uma análise da atividade de trabalho a partir de três ferramentas metodológicas: 1. Análise de documentos sobre as normas antecedentes/ prescrições 
do trabalho, 2. Visitas à UN (envolvendo observações da atividade e conversas informais com as auxiliares) e 3. Encontros sobre o trabalho com as auxiliares (constituindo o dispositivo Comunidade Ampliada de Pesquisa) para discussão e análise da atividade em relação com a sua saúde, a partir do diálogo entre saberes da experiência e conceitos científicos (Athayde, 2006; Brito, 2004). Através destes instrumentos produziu-se o material de análise da pesquisa.

8 As visitas ao meio de trabalho aconteceram em todos os diferentes horários de plantões (inclusive noturnos), com vistas a percorrer as diferentes situações e grupos e estabelecer uma aproximação inicial com as auxiliares e sua atividade de trabalho. Ao todo foram feitas dez visitas, nas quais observamos a atividade e estabelecemos conversas dialógicas com as auxiliares de enfermagem, produzindo material para a etapa posterior da pesquisa.

Após efectuar a análise das normas antecedentes e das observações e conversas travadas com as auxiliares durante as visitas, foram montados os encontros sobre o trabalho, nos quais discutimos com as trabalhadoras temas pertinentes às suas demandas, na busca de um diálogo sinérgico entre saberes científicos e saberes da prática, com vistas a compreendertransformar a atividade em foco. Foram realizados seis encontros de uma hora, dentro da jornada de trabalho, com a participação de nove auxiliares de um dos plantões (em um total de cerca de 100 auxiliares dos seis plantões), que se revezavam entre as reuniões em grupos de três a cinco participantes. Em cada encontro houve a apresentação das análises e dos conceitos utilizados, colocando-os em seguida em debate com a experiência das trabalhadoras, tendo como foco sua atividade de trabalho e a saúde (em concomitância com as exigências de produtividade e qualidade). A partir destas discussões, pôde-se problematizar/ (re) tratar questões invisibilizadas/ naturalizadas (pouco discutidas no cotidiano de trabalho) da atividade destas trabalhadoras, tais como : sua formação profissional, suas condições de trabalho, os coletivos de trabalho presentes e a organização do trabalho.

\section{Resultados}

\section{A formação profissional das auxiliares}

10 A transmissão de saberes e valores do ofício é feita principalmente "on the job", "de auxiliar para auxiliar" e contribui para a constituição e desenvolvimento de suas competências. Neste sentido, revelou-se que a atividade das auxiliares exige a aquisição de uma "desenvoltura" e uma coragem de "encarar de frente" os desafios e "passar por cima" do medo para se trabalhar com os bebês na Unidade Neonatal, envolvendo um aprendizado de saberes não apenas no plano cognitivo, como também nos planos corporal e afetivo.

11 Por outro lado, encontramos entre as auxiliares uma superqualificação formal (através da realização de cursos de graduação em enfermagem e mesmo pós-graduação, por muitas delas), não reconhecida em qualquer plano, mas que é, porém, utilizada no exercício da atividade, a partir de diversas exigências da própria organização do trabalho. Este dado nos parece relacionado com o fato de as participantes apresentarem uma forte demanda pela aprendizagem e a incorporação de um património teórico/ científico que embase suas práticas: vêem isto como meio de não trabalharem "no 
automático", e de poderem agregar autonomia (e quiçá mais valor/ reconhecimento social) às suas ações.

\section{A construção de coletivos no trabalho das auxiliares}

12 Identificamos a construção de um coletivo de trabalho das auxiliares, que possibilita relações de cooperação e coordenação entre elas. Notamos que esta cooperação aparece de forma mais intensa nas situações em que elas conquistaram uma relativa autonomia e parece prejudicada quando esta autonomia é impedida. Entretanto, entendemos que este coletivo apresenta-se um tanto isolado na inter-relação com os outros grupos que atuam na UN. Um exemplo disso aparece na relação conflituosa presente no coletivo formado com os familiares dos bebês para a co-produção do serviço, onde eles são convidados (e mesmo cobrados) a participar da realização do cuidado dos filhos. Neste caso, identificamos uma falta reconhecimento em via dupla : por um lado, as mães / os familiares muitas vezes demandam das auxiliares que estas "sintam o sofrimento igual" ao delas e não reconhecem / entendem o empenho das auxiliares em realizar um trabalho com produtividade e qualidade, nem dão sinais de reconhecimento da importância da atividade destas profissionais para o tratamento efetivo de seus filhos; por outro lado, as profissionais têm dificuldades em se confrontar com as inseguranças das mães e mesmo de reconhecer seu sofrimento, suas demandas afetivas, dúvidas, medos e angústias frente à situação crítica e inédita do filho. Conforme Dejours (1993), a dinâmica do reconhecimento apresenta-se como um meio de propiciar efetividade social ao trabalho realizado e de retribuição psicológica frente à identidade no mundo do trabalho. Deve-se pautar em dois sentidos: no de gratidão pela contribuição à organização do trabalho; e no de constatação da contribuição dos sujeitos para a organização do trabalho e, assim, de tomada de consciência das insuficiências e falhas do processo técnico e da concepção da organização do trabalho.

\section{A organização real do trabalho das auxiliares}

13 Através da construção histórica de um coletivo de ofício, foram criadas regras profissionais para o desenvolvimento das atividades frente às insuficiências da organização prescrita e das condições de trabalho. Na invenção de regras (no interior das quais bricolagens, como "chupetinha" feita de luvas, "rolinho" de cobertor e adaptações de materiais), algumas apresentam condições relativas de visibilidade entre as próprias auxiliares e possibilitam a transgressão coletiva das normas antecedentes (Schwartz \& Durrive, 2007) do trabalho, em consonância com os valores do ofício destas trabalhadoras. Destacamos a construção de um patrimônio de saberes e valores ("fazer sempre o melhor" / buscar a "perfeição"; ter a saúde da criança em primeiro lugar ; ser "brigonas" por melhores condições e formas de organização do trabalho ; ter "coração de mãe"), formando e mobilizando um gênero profissional (Clot, 2006) das auxiliares, que se desenvolve e se transmite entre elas, passando por julgamento em seu coletivo, o que contribui para a proteção da saúde e para a realização de um trabalho com a qualidade e a produtividade pertinentes. Por parte da hierarquia verificamos insuficiente (re) conhecimento / avaliação do trabalho, o que fica claro pela fragilidade dos treinamentos recebidos e pela má qualidade dos materiais fornecidos. 


\section{A má qualidade dos instrumentos de trabalho e o risco "subjetivo" à saúde das auxiliares}

trabalho relacional de cuidado. As más condições dos instrumentos de trabalho oferecidos (ex: jelcos e seringas de má qualidade, incubadoras sem manutenção), apesar de apresentarem-se como condições simplesmente materiais parecem representar claramente o quanto o trabalho das auxiliares é invisibilizado e mobiliza um forte componente afetivo para se efetivar. Tais condições precárias exigem inventividade e improvisação contínuas - o que viabiliza (precariamente) a efetivação do trabalho de cuidado, mas, contraditoriamente, contribui para a manutenção de más condições. Neste sentido, fere-se os valores e normas do coletivo das auxiliares, gerando problemas tanto na saúde dos bebês (mais perfurados do que o necessário com jelco ruim, por exemplo), quanto das auxiliares (que ficam "mal emocionalmente", sentem em si a dor das crianças, ficam "cansadas", "estressadas", não ficam com a "cabeça legal").

\section{Considerações Finais}

Entendemos que as competências necessárias para a realização do trabalho de cuidado na UN decorrem de uma mobilização sinérgica de conhecimentos teórico-técnicos estruturados (os quais as trabalhadoras demandam) e da utilização da inteligência da prática (Dejours, 1997), voltada à dimensão relacional da atividade. No entanto, esta última, embora fundamental no trabalho das auxiliares, é invisibilizada e desvalorizada enquanto competência desenvolvida no cotidiano das trabalhadoras. Ao contrário, ao se contar com a mobilização do corpo-si para o pleno desempenho da atividade das auxiliares, isso ocorre de forma naturalizada, desconsiderando-se os processos que levaram ao desenvolvimento desta competência e os custos para a saúde envolvidos nesta mobilização. Notamos também que a atividade relacional fica invisibilizada pela intensidade com a qual as trabalhadoras se envolvem emocionalmente com o trabalho de cuidado, dando tudo de si para que os resultados sejam alcançados, o que acreditamos estar fortemente associado à divisão sexual do trabalho (considerada uma importante norma antecedente), em que o "cuidar" é atribuído às mulheres. Paradoxalmente, este empenho dificulta a transformação das condições que precarizam sua atividade e prejudicam a sua saúde, na medida em que oculta as dificuldades existentes. Desta forma, o que é visível é o que deixa de ser feito, a ausência de uma tarefa realizada e não os esforços empreendidos na sua realização.

ditamos que a postura do coletivo de auxiliares frente às questões explicitadas acima pode estar representando uma forma (ainda que precária) de defesa da saúde, através de um sistema defensivo de tipo ideológico (Athayde, 1996), o qual se reflete no relativo isolamento apresentado por este grupo frente aos demais que atuam na UN. 


\section{BIBLIOGRAFIA}

Athayde, M. (1996). Gestão de Coletivos de Trabalho e Modernidade : Questões para a Engenharia de Produção. Tese de Doutorado, COPPE/ Universidade Federal do Rio de Janeiro, Rio de Janeiro.

Athayde, M. (2006). Uma proposta de orientação epistemológica, teórica e metodológica para a pesquisa-intervenção no campo do trabalho humano do ponto de vista da atividade e da dialogia. Texto para discussão, Programa de Pós-Graduação em Psicologia Social/UERJ, Rio de Janeiro, (inédito)

Brito, J. (2004). Saúde do trabalhador : reflexões a partir da abordagem ergológica. In M. Figueiredo, M. Athayde, J. Brito \& D. Alvarez (Orgs.). Labirintos do trabalho : interrogações e olhares sobre o trabalho vivo (pp. 91-114). Rio de Janeiro : DP\&A.

Canguilhem, G. (2002). O normal e o patológico. Rio de Janeiro : Forense Universitária.

Clot, Y. (2006). A função psicológica do trabalho. Petrópolis : Editora Vozes.

Daune-Richard, A. M. (2003). Qualificações e representações sociais. In H. Hirata \& M. Maruani (Orgs.). As novas fronteiras da desigualdade : homens e mulheres no mercado de trabalho. São Paulo : Editora SENAC. (pp. 65-76).

Dejours, C. (1993). Coopération et construction de l'identité en situation de travail. Futur antérieur, 16, 2, 41-52. Retirado em Janeiro, 02, 2007, de http://multitudes.samizdat.net/ Cooperation-et-cons- truction-de-l.html.

Dejours, C. (1997). O fator humano. Rio de Janeiro : Editora Fundação Getúlio Vargas.

Dejours, C. (2004). Adendum - Da Psicopatologia à Psicodinâmica do Trabalho. In S. Lancman \& S. Laerte (Orgs.). Christophe Dejours : Da psicopatologia à psicodinâmica do trabalho. Rio de Janeiro : Editora Fiocruz, Brasília : Paralelo 15. (pp. 47-104).

Guérin, F., Laville, A., Daniellou, F., Durrafoug, J., \& Kerguelen, A. (2001). Compreender o Trabalho para Transformá-lo. A Prática da Ergonomia. São Paulo : Editora Edgard Blücher Ltda.

Kergoat, D. (1996). Relações sociais de sexo e divisão sexual do trabalho. In M. J. Lopes, D. Meyer \& V. Waldow (Orgs.). Gênero e saúde. Porto Alegre : Artes Médicas. (p 19-28).

Oddone, I., Marri, G., Glória, S., Briante, G., Chiatella, M., \& Re, A. (1986). Ambiente de trabalho : a luta dos trabalhadores pela saúde. São Paulo : Editora Hucitec.

Scavone, L. (2005). O trabalho das mulheres pela saúde : cuidar, curar, agir. In W. Villela \& S. Monteiro (Orgs.) Gênero e saúde : Programa de Saúde da Família em questão. São Paulo : ABRASCO/UNFPA/Arbreit Factor. (p. 99-109).

Schwartz, Y. (2000). Trabalho e uso de si. Pro-posições, 11, 32, 34-50. Schwartz, Y., \& Durrive, L. (Orgs.). (2007). Trabalho e Ergologia : conversas sobre a atividade humana. Niterói : Eduff.

Zarifian, P. (2001). Objetivo Competência : por uma nova lógica. São Paulo : Atlas. 


\section{AUTOR}

\section{LETÍCIA PESSOA MASSON}

Rua João Alfredo, 37/ 101, Tijuca, Rio de Janeiro/ RJ, CEP : 20511-390, Brasil

leticiapessoa@yahoo.com.br 